\title{
HIPPOCAMPAL SLOW ("AROUSAL") WAVE ACTIVATION IN THE ROSTRAL MIDBRAIN TRANSECTED CAT ${ }^{1}$
}

\author{
Hiroshi Kawamura and Edward F. Domino \\ Michigan Neuropsychopharmacology Research Program, Department of Pharmacology, University of Michigan, \\ Ann Arbor, Mich. 48104, and Lafayette Clinic, Detroit, Mich. 48207 (U.S.A.)
}

(Accepted for publication: March 7, 1968)

The role of the hypothalamus in controlling the level of consciousness is well known (von Economo 1928; Ranson and Magoun 1939; Murphy and Gellhorn 1945; Ingram et al. 1951). Destruction of the hypothalamus is associated with behavioral as well as EEG disturbances. In the past two decades, extensive studies on the physiological functions of the brain-stem reticular formation (Moruzzi and Magoun 1949; Magoun 1952 and many others) have shown that this structure is essential for controlling the activity level of the brain. The hypothalamus is considered by some investigators to be a rostral end structure of the brain-stem activating system. However, a continuous EEG sleep pattern with spindle bursts was observed in an intercollicularprepontine transected preparation (Bremer 1935,1938 ), a finding which is compatible with the essential role of the midbrain reticular formation for activation of the forebrain (Moruzzi and Magoun 1949). Later, the findings of Batsel (1960) and Villablanca (1965), showing a spontaneous neocortical EEG desynchronizing pattern beginning more than a week after brainstem transection, suggested that some kind of activating mechanism is functioning in the remaining telencephalon-diencephalon. Presumably this involves the hypothalamus. Yet it is paradoxical that even though the latter structure is intact in an acute midbrain transected preparation, a neocortical sleep EEG pattern is still seen. A question therefore arises about the individual roles and relationships between the hypothalamus and the midbrain reticular formation in the activation of the neocortex.

1 Supported in part by grant MH-11846.
Another problem, discussed by Bremer (1957), is whether a single, common or individual mechanisms control the neocortex and limbic system. The hippocampal regular slow "arousal" waves and the neocortical low voltage fast waves are ordinarily associated, although in the transition from wakefulness to sleep these two patterns can be dissociated (Green and Arduini 1954). Arduini and Pompeiano (1955) mentioned the appearance of the hippocampal "arousal" wave with a neocortical sleep pattern in the acute cerveau isolé rabbit. A similar dissociation between the hippocampal and neocortical EEG was reported in the emotionally stressed chronic cat by Passouant et al. (1955). Evidence of the existence of a powerful influence of the hypothalamus on limbic system activation has been provided (Tokizane et al. 1960; Kawamura et al. 1961; Kawamura and Oshima 1962). This paper will elucidate the functional role of the hypothalamus and midbrain reticular formation upon the ascending activating system with respect to neocortical and hippocampal EEG activation. The peculiar EEG characteristics of the acute forebrain preparation in which the junction between the diencephalon and midbrain is transected will also be discussed.

\section{METHODS}

Of thirty-five cats of both sexes $(2.5-4.5 \mathrm{~kg})$, useful experiments were obtained in twenty-one. Under diethyl ether anesthesia, a tracheotomy was performed and the cat mounted in a stereotaxic apparatus. A forearm vein was cannulated for drug injection. After local infiltration with $2 \%$ Xylocaine, a large trephine hole was made

Electroenceph. clin. Neurophysiol., 1968, 25:471-480 
with a dental drill and bone rongeur to expose the latero-posterior portion of the brain. Immediately before transection, ether anesthesia was discontinued, and decamethonium or gallamine was given i.v. To minimize cerebral edema, 10-15 $\mathrm{ml}$ of $20 \%$ mannitol solution (Osmitrol) was injected i.v. In several cases, cisternal drainage was accomplished. Blood pressure was recorded from the femoral artery by a Statham transducer connected to one channel of the polygraph. After opening the dura mater, the superior colliculus was exposed by retraction of the overlying tissues, and its junction with the thalamus was severed to just caudal to the mammillary body, first on one, then on the other side. In most cases, the rostral end of the midbrain rather than the caudal end of the diencephalon was transected (histological confirmation); hence, the term "rostral midbrain transection" (RMT) was adopted. To test completeness of transection, the desired ineffectiveness of hypothalamic stimulation in altering blood pressure and failure of nociceptive or other peripheral stimuli to alter the EEG were checked routinely before each experiment.

The neocortical EEG was recorded using phonograph needle electrodes placed on the skull overlying the frontal and parietal cortices. In some cases, the frontal bone was used as a reference point. For recording the hippocampal
EEG and stimulating the brain-stem, concentric bipolar needle electrodes insulated with epoxylite except at the tips ( $1.5 \mathrm{~mm}$ separation) were inserted stereotaxically according to the atlas of Jasper and Ajmone Marsan (1954). For recovery of good hippocampal EEG recordings after surgery, 2-3 h elapsed before starting the experiment. Body temperature was checked by a rectal thermometer and maintained at $37-38^{\circ} \mathrm{C}$ with a heating pad placed under the animal.

EEGs were recorded by a Grass Model 7 polygraph (time constant: $0.1 \mathrm{sec}$ ). Square, 1 msec pulses at $100 / \mathrm{sec}$ were delivered from a Grass S8 stimulator. At the end of an experiment, the brain was perfused with $10 \%$ formalin. Completeness of transection and electrode locations were verified histologically, using thioninestained serial sections.

\section{RESULTS}

\section{EEG of the cat with RMT}

The neocortical EEG of the immobilized intact cat consists of relatively small amplitude, slow waves intermittent with spindle bursts and low voltage, high frequency waves. The latter patterns are associated with the hippocampal "arousal" waves which, under the conditions of an acute experiment, were not limited to the



Fig. 1

EEG patterns of the neocortex and hippocampus from an intact cat $(A$ and $B)$ and from the same cat after rostral midbrain transection $(C$ and $D)$.

$A$ : Arousal pattern. $B$ : Drowsy pattern. $C: 3 \mathrm{~h}$ after RMT: dissociation of EEG in the hippocampus ("arousal") and neocortex (large amplitude slow wave "sleep") after hypothalamic stimulation. $D$ : Spontaneous large amplitude, slow waves with spindle bursts in the neocortex and irregular fast and slow wave activity in the hippocampus. Abbreviations in this and following illustrations: L.FC-PC and R.FC-PC, left and right frontal cortex-parietal cortex; L.FC and R.FC, left and right frontal cortex-frontal bone; L.HPC, left hippocampus; EKG, electrocardiogram. 
theta range but also included slower waves. Hence in this paper, the term "arousal" wave will refer to the regular slow $(1.5-7 \mathrm{c} / \mathrm{sec})$ waves which in the intact cat are associated with neocortical low voltage, fast patterns (Fig. 1, $A$ ). When slow waves and spindle bursts increased at the neocortical level, regular slow "arousal" waves tended to disappear and rather irregular fast activity increased in the hippocampus (Fig. 1, $B)$.

After RMT, the neocortex almost immediately exhibited slow waves and spindle bursts, and within several minutes very large amplitude and often quite regular slow waves (over $100 \mu \mathrm{V}$ ) became predominant. This pattern then alternated with one consisting of irregular slow waves and frequent spindle bursts (normally associated with sleep), with the latter pattern progressively increasing in duration. Hippocampal "arousal" waves disappeared after transection and only irregular fast activity (mostly $10-20 \mathrm{c} / \mathrm{sec}$ ) with occasional irregular slow waves could then be seen (Fig. 1, D). The most characteristic feature of the RMT preparation was the ease in obtaining hippocampal "arousal" waves, compared to the difficulty in producing neocortical desynchronization (Fig. 1,C) either by electrical stimulation of the hypothalamus (see below) or by systemic injection of some centrally acting drugs (Kawamura and Domino, in preparation).

Visual stimuli did not activate the electrical activity of either the neocortex or the hippocampus in this preparation ( 5 cases). Olfactory stimulation (blowing air into the ipsilateral nostril) did induce olfactory responses (15-20 $\mathrm{c} / \mathrm{sec}$ waves) in the hippocampus during and after the stimulus, but neither neocortical nor hippocampal "arousal" was observed (8 cases). Neocortical electrical stimulation also failed to activate the hippocampal pattern ( 3 cases).

\section{Effect of posterior hypothalamic stimulation in the RMT preparation}

The most consistent finding in this preparation was that high frequency, electrical stimulation of the posterior hypothalamus (generally at stereotaxic coordinates A 10, L 1-2, H 3-5 at moderate intensity) induced long duration "arousal" patterns in the hippocampus without desynchronization of the neocortex (Fig. 2). Such hippocampal arousal waves, which outlasted the cessation of hypothalamic stimulation, were observed in thirteen out of twenty-one cats. When the neocortical background activity showed a large amplitude, slow wave sleep pattern, hypothalamic stimulation would suppress slow waves and enhance spindle bursts (Fig. 3, upper traces), but fail to produce desynchronization. On the

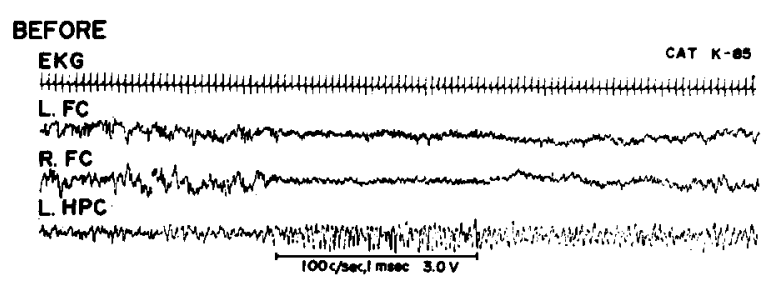

AFTER ROSTRAL MIDBRAIN TRANSECTION

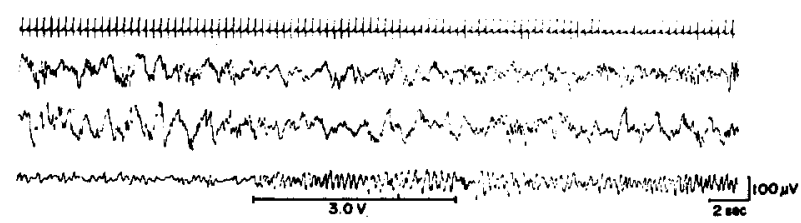

Fig. 2

Effects of posterior hypothalamic stimulation before and after rostral midbrain transection. Upper traces: Before transection. Posterior hypothalamic stimulation $(100 \mathrm{c} / \mathrm{sec}, 1 \mathrm{msec}, 3.0 \mathrm{~V})$ induced low voltage fast waves in the neocortex and regular slow "arousal" waves in the hippocampus. Lower traces: After transection. Stimulation (3.0 V) did not desynchronize the neocortical EEG but elicited tonic hippocampal "arousal" waves. 


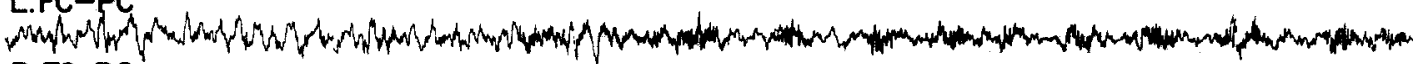
R. FC $\rightarrow$ C

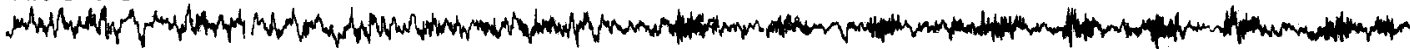

L.HPC $100 \mathrm{csec}, 1 \mathrm{msec}, 4 \mathrm{~V}$

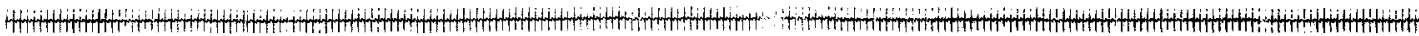

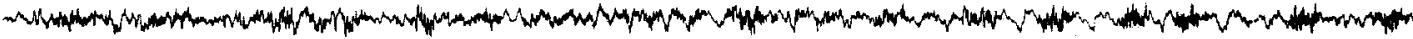

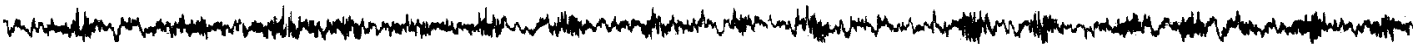

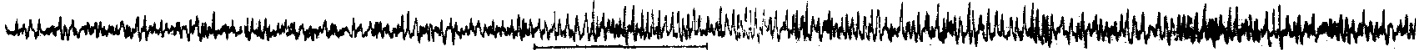

Fig. 3

Tonic hippocampal "arousal" waves after posterior hypothalamic stimulation in a rostral midbrain transected cat.

Upper traces: Suppression of slow waves and enhancement of repetitive spindie bursts in the neocortex were obtained after posterior hypothalamic stimulation $(100 \mathrm{c} / \mathrm{sec}, 1 \mathrm{msec}, 4 \mathrm{~V})$. Lower traces: Less change in the neocortical EEG with little background slow waves before stimulation. Enhancement of spindle bursts is seen after stimulation. Hippocampal " ousal" waves continued for $2 \mathrm{~min}$ in both cases.

ROSTRAL MIDBRAIN TRANSECTION



Fig. 4

Phasic desynchronization of the neocortex by strong hypothalamic stimulation in the rostral midbrain transected cat.

Lower intensity stimulation ( $3 \mathrm{~V}$ ) induces hippocampal "arousal" without desynchronization of the neocortex. With a high intensity ( $5 \mathrm{~V})$ stimulus, brief desynchronization in the neocortex is observed. Hippocampal "arousal" lasts much longer. 




Fig. 5

Comparison of thalamic and hypothalamic stimulation on the EEG of the neocortex and hippocampus of a rostral midbrain transected cat.

Abscissa: Depth of electrode in the diencephalon. $+4,4 \mathrm{~mm}$ above the 0 line (thalamus), $-4,4 \mathrm{~mm}$ below the 0 line (hypothalamus) at $10 \mathrm{~mm}$ anterior from 0 plane and $2 \mathrm{~mm}$ lateral from median line. Ordinate: Voltage of stimulus $(100 \mathrm{c} / \mathrm{sec}, 1 \mathrm{msec})$. The threshold for hippocampal "arousal" wave induction is low in the hypothalamus and the frequency and amplitude of the wave are higher during hypothalamic stimulation. The threshold for desynchronization of the neocortex is much lower in the thalamus.

other hand, when the background activity of the neocortex showed few slow waves and frequent spindle bursts, even though hippocampal activity revealed the same "arousal" pattern upon hypothalamic stimulation, the change in the neocortical EEG pattern was much less apparent. Only a slight change in the interval between spindle bursts was seen (Fig. 3, lower traces). Hippocampal regular slow waves without neocortical desynchronization could persist in both circumstances up to $2 \mathrm{~min}$ following cessation of posterior hypothalamic stimulation.

Such a dissociation in the EEG activity level between the neocortex and the hippocampus was produced over a wide range of stimulus intensities above threshold voltage. If the intensity of the stimulus was increased markedly, a very brief phasic desynchronization of the neocortex was observed during stimulation (Fig. 4).
Comparison of the activating effect of the thalamus and hypothalamus

In seven cats, an electrode was advanced millimeter by millimeter from the thalamus to hypothalamus, and, at the threshold voltage, the activating effect on the neocortex and hippocampus was recorded at each point. Fig. 5 illustrates a typical result. It can be seen that upon stimulation of the hypothalamic area (especially $H=-2$ ), the hippocampal "arousal" waves were more frequent and of larger amplitude than those that occurred with thalamic stimulation of the same intensity (see also Fig. 6). In the RMT preparation, the diencephalic areas which produced hippocampal "arousal" waves more easily than neocortical desynchronization were distributed in the hypothalamus ( $n$. hypothalamicus dorsalis, $n$. hypothalamicus posterior, $n$. hypothalamicus lateralis, $n$. hypothalamicus anterior

Electroenceph. clin. Neurophysiol., 1968, 25: 471-480 


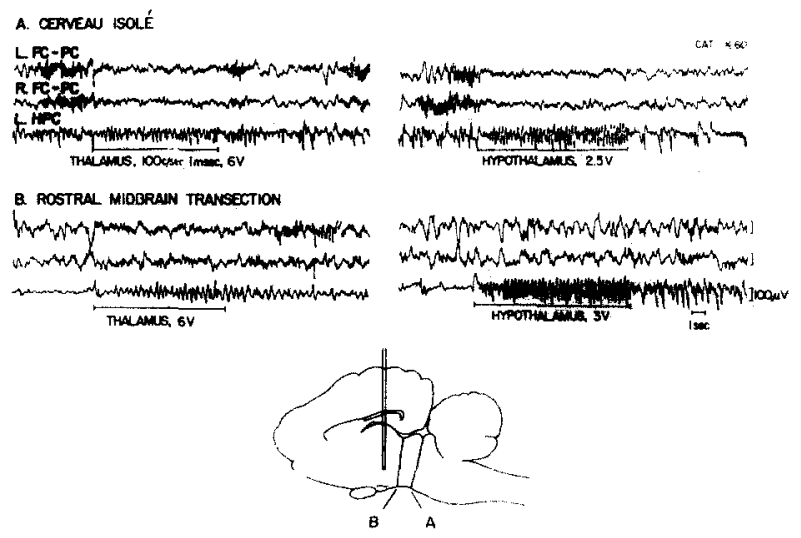

Fig. 6

Effects of thalamic and hypothalamic stimulation on neocortical and hippocampal EEG in a cerveau isole and rostral midbrain transected cat (see Fig. 7).

In the cerveau isole preparation $(A)$, posterior hypothalamic stimulation induced hippocampal "arousal" as well as neocortical desynchronization. A subsequent rostral midbrain transection (B) prevented neocortical desynchronization by hypothalamic stimulation.

and $\mathrm{n}$. hypothalamicus ventromedialis).

In the RMT preparation, stimulation of the subthalamus did not produce significant tonic desynchronization of the neocortex.

\section{Comparison between RMT and cerveau isolé}

In the intercollicular-prepontine preparation (cerveau isolé; Bremer 1935), hypothalamic stimulation induced neocortical desynchronization more readily than in the RMT preparation in all four cats tested. Thus, the more caudal the transection of the midbrain, the easier the production of neocortical EEG activation by hypothalamic stimulation. Neocortical desynchronization by olfactory stimuli was also obtained when the transection of the midbrain was more caudal than in RMT. In the RMT preparation, however, olfactory stimulation did not produce activation of the neocortex. These data indicate that the midbrain reticular formation is very important for the activation of the neocortex. On the other hand, the hippocampal "arousal" wave could be induced and lasted a relatively long time ( $5 \mathrm{sec}-$ $2 \mathrm{~min}$ ) after cessation of hypothalamic stimulation in the forebrain preparation lacking the midbrain reticular formation (RMT). Fig. 6 illustrates the different effects of thalamic and hypothalamic stimulation on the neocortical and hippocampal EEG taken from the same cat both in a cerveau isole and in a subsequent RMT prep-

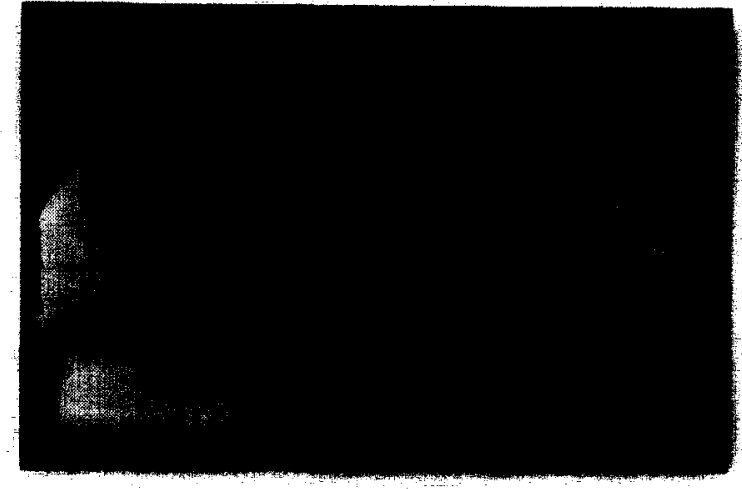

Fig. 7

Cat brain with transection of brain-stem at two different levels. The transection on the left is at the rostral midbrain and that on the right a cerveau isolé. The EEG recording of Fig. 6 was taken from this brain.

aration. Fig. 7 shows the level of transections in the midbrain of this animal.

\section{DISCUSSION}

The ascending reticular activating system consists of the reticular formation which extends caudally from the midbrain to the spinal cord and rostrally connects to the hypothalamus, subthalamus and ventro-medial thalamus in the diencephalon. Lesions of either the midbrain tegmentum or the junction of the hypothalamus and thalamus induce a large amplitude, slow

Electroenceph. clin. Neurophysiol., 1968, 25: 471-480 
wave neocortical EEG in the acute cat (Lindsley et al. 1949) as well as in the chronic animal in association with comatose behavior (Lindsley et al. 1950). Although in an earlier paper (Bowden et al. 1949) the role of the hypothalamus had been given greater stress, the discovery of the crucial role of the midbrain reticular formation in the induction of spindle bursts (proved by lesion experiments) led more attention to this structure. According to Starzl et al. (1951), the regions in the brain-stem that yield generalized neocortical desynchronization upon stimulation include the midbrain reticular formation, the internal capsule, the subthalamus, a part of the ventral thalamus, and the dorsal part (but not the ventral portion) of the hypothalamus. Jasper's (1949) concept of a diffuse thalamic projection system suggested a functional connection between this system and the midbrain reticular formation, thus dividing the diencephalic end of the reticular activating system into the thalamic pathway (non-specific thalamic nuclei) and the extrathalamic pathway (hypothalamus and subthalamus). Since after a massive lesion of the thalamus (which will result in deterioration of the neocortical EEG) no real desynchronization is induced by extrathalamic activation (see Starzl et al. 1951), the thalamic pathway appears to be more important in desynchronization of the neocortex than the extrathalamic pathway.

As for the induction of the hippocampal regular slow waves by diencephalic stimulation, Green and Arduini (1954) noticed no difference in the rabbit between stimulating the thalamus and hypothalamus. Later, using the evoked potential technique, Green and Adey (1956) found that the fast response was conducted from a wide hypothalamic area to the hippocampus, while the intralaminar and anterior nuclei were the only thalamic areas exerting a similar effect. The short latency response from the anterior thalamic nuclei to the hippocampus could be explained by the possibility of direct fiber connections from the mammillothalamic tract to the hippocampus, as suggested by Green and Adey (1956). Since this earlier research was done with evoked responses in the hippocampus, no comparisons of the stimulation effects of thalamic and hypothalamic areas on the neocortex and hippocampus were made. The present study (see also Tokizane et al. 1960) revealed a critical difference in effects of stimulation from the hypothalamus and the non-specific thalamic nuclei; high frequency, electrical stimulation of the posterior hypothalamus with threshold intensity readily induced hippocampal slow waves without a marked change in the neocortical EEG, whereas intralaminar thalamic stimulation induced marked desynchronization in the neocortex with less of a change in the hippocampus. The data of Corazza and Parmeggiani (1963), and Parmeggiani (1967) are consistent with these findings. According to them, a medial hypothalamic lesion would, but a lateral hypothalamic or thalamic lesion would not, block the hippocampal "arousal" waves. The critical role of the midbrain reticular formation in producing tonic desynchronization of the neocortex is proven in the RMT forebrain preparation which totally lacks the midbrain reticular formation. Only stimulation of the midline thalamic area induced phasic desynchronization of the neocortex in the RMT. Posterior hypothalamic stimulation hardly desynchronized the neocortical EEG in the RMT preparation, whereas it did so in the cerveau isolé preparation (which contains a part of the midbrain). These data are in accord with those of Schlag and Chaillet (1963) who reported abolition of tonic desynchronization of the neocortex by midline thalamic stimulation after destruction of the posterior commissure area. Furthermore, they suggest that the posterior hypothalamus desynchronizes the neocortex not through a direct pathway but via the midbrain, possibly through the reticular formation. Also the subthalamus does not induce a significant desynchronization of the neocortex compared to the easily obtained desynchronization induced by midline thalamic stimulation. Earlier lesion experiments (Kawamura et al. 1961; Feldman and Waller 1962) also suggest that tonic desynchronization of the neocortex induced by stimulation of the midbrain reticular formation is mainly conducted through the midline thalamic nuclei. The hypothalamic or subthalamic pathway (extrathalamic) plays a secondary, less important role for tonic desynchronization of the neocortex. Data from the RMT preparation provide evidence that there is a strong flow of impulses from the hypothalamus and subthala- 
mus to the midbrain reticular formation and that this influence enhances tonic desynchronization of the neocortex via the thalamus. This may explain why similar neocortical EEG slowing was obtained after lesions of either the posterior hypothalamus or the midbrain reticular formation.

In contrast to the difficulty of inducing neocortical desynchronization, it is a peculiar characteristic of the RMT preparation that a relatively long lasting, hippocampal, regular, slow wave pattern may be induced readily by hypothalamic stimulation. From this it can be inferred that the hypothalamus is not only the main pathway of activation from the midbrain reticular formation to the hippocampus, but that it also has a sustained activating mechanism itself for producing hippocampal "arousal" waves. After massive lesions of the hypothalamus, even intense stimulation of a peripheral nerve or the caudal reticular formation could not induce hippocampal "arousal" waves in the acute cat (Kawamura et al. 1961) This finding indicates that although the septum has a pacemaker role in the appearance of the hippocampal regular slow waves (Brücke et al. 1959a, b), such pacemaking activity functions only when a constant inflow of impulses from the hypothalamus and reticular formation is provided. In this sense, the relationship of the septum to the hippocampus is similar to that of the non-specific thalamic nuclei to the neocortex. Both relay a tonic activating effect to each cortex, and have to some extent their own pacemaker activity. The sustained activating mechanism in the hypothalamus, as revealed by the hippocampal EEG in the RMT preparation, is somewhat limited because of a slightly lower frequency of hippocampal "arousal" waves, shorter duration of the regular slow waves after the same intensity stimulation, and difficulty of eliciting activation by olfactory or visual stimuli. The existence of a persistent activating mechanism in the hypothalamus would explain why the spontaneous desynchronization pattern appears 1 week after surgery in the chronic RMT dog (Batsel 1960) and cat (Villablanca 1965). In the acute preparation, fiber connections between the hypothalamus and the neocortex are not sufficiently facilitated to produce activation, but after the passage of a week or more this pathway might conceivably become facilitated, as a result of denervation supersensitivity.

\section{SUMMARY}

The neocortical and hippocampal EEG changes of an acute rostral midbrain cat preparation (brain-stem section at the junction of the diencephalon and midbrain) are described.

1. In the neocortex an alternation of very regular, large amplitude slow waves $(0.5-1.5$ $\mathrm{c} / \mathrm{sec}$ ) without prominent spindle bursts, with irregular high voltage slow waves with repetitive spindle bursts was seen.

2. The hippocampal EEG showed a continuous pattern of irregular fast waves with occasional slow waves. Posterior hypothalamic stimulation elicited hippocampal "arousal" waves $(1.5-3.5 \mathrm{c} / \mathrm{sec})$ which lasted from $5 \mathrm{sec}$ to $2 \mathrm{~min}$ after the cessation of the stimulus, while the neocortex did not show the EEG desynchronization which could be elicited before transection. Depending upon the intensity of the hypothalamic stimulus and the pattern of background activity before stimulation, the neocortex also showed some change, from slight to marked suppression of slow waves with enhancement of spindle bursts. Desynchronization of the neocortex by hypothalamic stimulation was observed only briefly during extremely strong stimuli.

3. Thalamic stimulation elicited phasic desynchronization in the neocortical EEG with a less marked change in the hippocampal EEG, whereas hypothalamic stimulation induced stronger regular slow wave activation in the hippocampus (hippocampal "arousal" waves) with a lesser change in the neocortex.

4. In the classic cerveau isole preparation, hypothalamic stimulation could elicit brief neocortical desynchronization as well as hippocampal "arousal". With a more rostral transection (at the junction between diencephalon and mesencephalon), it was very difficult to produce neocortical desynchronization by posterior hypothalamic stimulation which, however, produced marked hippocampal "arousal" waves.

5 . It is concluded that for activation of the hippocampus, the hypothalamus is not only the primary pathway receiving impulses from the 
midbrain reticular formation, but it also possesses a sustained activating mechanism for the hippocampus. This tonic activating mechanism may influence the neocortex through the midbrain reticular formation. There seems to be no important direct activating pathway to the neocortex from the hypothalamus under the conditions of an acute experiment.

\section{RÉSUMÉ}

ACTIVATION HIPPOCAMPIQUE $\dot{A}$ ONDES LENTES (“AROUSAL") DANS LA TRANSECTION DU CERVEAU MOYEN DU CHAT

Les variations EEG néocorticales et hippocampiques d'une préparation aiguë du cerveau moyen rostral du chat (section cérébral à la jonction du diencéphale et du cerveau moyen) sont décrites.

1. Dans le néocortex une altération d'ondes lentes d'amplitude régulièrement très grande sans bouffée de fuseau proéminent, avec des ondes lentes de haut voltage irrégulières avec des bouffées répétitives de fuseaux.

2. L'EEG hippocampique montre une forme irrégulière d'ondes rapides avec des ondes lentes occasionnelles. La stimulation de l'hypothalamus postérieur détermine un "arousal" hippocampique (ondes de 1,5 à $3,5 \mathrm{c} / \mathrm{sec}$ ) qui dure de $5 \mathrm{sec}$ à 2 min après la cessation du stimulus, tandis que le néocortex ne montre pas de désynchronisation EEG qui puisse être produite après transection. Dépendant de l'intensité du stimulus hypothalamique et de la forme de l'activité de fond avant stimulation, le néocortex montre aussi de telle variation, de suppression légère à suppression marquée avec élévation des bouffées de fuseaux. La désynchronisation du cortex par stimulation hypothalamique est observée seulement de façon brève pendant des stimuli très forts.

3. La stimulation thalamique détermine une désynchronisation phasique de l'EEG néocortical avec un changement moins marqué de l'EEG hippocampique, tandis que la stimulation hypothalamique induit une activation à ondes lentes régulières plus forte dans l'hippocampe (ondes "d'arousal" hippocampique) avec un changement moindre dans le néocortex.
4. Dans la préparation classique "cerveau isolé", la stimulation hypothalamique' pourrait déterminer une brève désynchronisation néocorticale aussi bien que l'"arousal" hippocampique. Avec une transection plus rostrale (à la jonction entre le diencéphale et le mésencéphale) il est très difficile de produire une désynchronisation néocorticale par stimulation de l'hypothalamus postérieur qui produit, cependant, des ondes marquées d"“arousal" hippocampique.

5. Les auteurs concluent que pour l'activation de l'hippocampe, l'hypothalamus n'est pas seulement le passage primaire recevant des impulsions de la formation réticulée du cerveau moyen mais possède aussi un mécanisme activateur soutenu de l'hippocampe. Ce mécanisme activateur tonique peut influencer le néocortex à travers la formation réticulaire du cerveau moyen. Il ne semble pas exister de voie importante activatrice directe vers le néocortex depuis l'hypothalamus dans les conditions d'une expérience aiguë.

\section{REFERENCES}

Arduin, A. A. e Pompeiano, O. Attività elettrica di singole unità dell'ippocampo e sue modificazioni con stimoli afferenti. Arch. Sci. biol. (Bologna), 1955, 39: 397-406.

BATSEL, H. L. Electroencephalographic synchronization and desynchronization in the chronic "cerveau isole" of the dog. Electroenceph. clin. Neurophysiol., 1960, $12: 421-430$.

Bowden, J. W., Lindsley, D. B. and Magoun, H. W. Diencephalic influences upon cortical electrical activity. Anat. Rec., 1949, 103: 427.

Bremer, F. Cerveau isolé et physiologie du sommeil. C.R. Soc. Biol. (Paris), 1935, 118: 1235-1241.

Bremer, F. L'activité électrique de l'écorce cérébrale et le problème physiologique du sommeil. Boll. Soc. ital. Biol. sper., 1938, 13: 271-290.

Bremer, F. De quelques problèmes posés par la physiopathologie des altérations de la conscience. lst. int. Congr. Neurol. Sci., Bruxelles, 1957: 49-66.

Brücke, F., Petsche, H., Pillat, B. und Deisenhammer, E. Ein Schrittmacher in der medialen Septumregion des Kaninchengehirns. Pflügers Arch. ges. Physiol., 1959a, 269: 135-140.

Brücke, F., Petsche, H., Pillat, B. und Deisenhammer, E. Die Beeinflüssung der "Hippocampus-arousalReaktion" beim Kaninchen durch elektrische Reizung im Septum. Pflügers Arch. ges, Physiol,, 1959b, 269: 319-338.

Corazza, R. and Parmeggian, P. L. Central course of the afferent system eliciting the theta rhythm in the cat's hippocampus upon ischiatic stimulation. Helv.

Electroenceph. clin. Neurophysiol., 1968, 25: 471-480 
physiol. pharmacol. Acta, 1963, 21 : C10-C12.

Economo, C. von, Théorie du sommeil. J. Neurol. Psychiat. (Brux.), 1928, 28: 437-464.

Feldman, S. M. and Waller, H. J. Dissociation of electrocortical activation and behavioral arousal. Nature (Lond.), 1962, 196: 1320-1322.

Green, J. D. and Adey, W. R. Electrophysiological studies of hippocampal connections and excitability. Electroenceph. clin. Neurophysiol., 1956, 8: 245-262.

Green, J. D. and ARDuinI, A. A. Hippocampal electrical activity in arousal. $J$. Neurophysiol., 1954, 17: 533557.

IngRam, W. R., KNOTT, J. R., WheATley, M. D. and SUMmers, T. D. Physiological relationship between hypothalamus and cerebral cortex. Electroenceph. clin. Neurophysiol., 1951, 3: 37-58.

$J_{\text {ASPER, }} H$. H. Diffuse projection systems: the integrative action of the thalamic reticular system. Electroenceph. clin. Neurophysiol., 1949, 1: 405-420.

JASPER, H. H. and AJMONE MARSAN, C. A stereotaxic atlas of the diencephalon of the cat. Nat. Res. Council of Canada, Ottawa, 1954.

Kawamura, H., Nakamura, Y. and Tokizane, T. Effect of acute brain stem lesions on the electrical activities of the limbic system and neocortex. Jap. J. Physiol., 1961, 11: 564-575.

Kawamura, $H$. and Oshima, $K$. Effect of adrenaline on the hypothalamic activating system. Jap. J. Physiol., 1962, 12: 225-233.

Lindsley, D. B., Bowden, J. W. and Magoun, H. W. Effect upon the EEG of acute injury to the brain stem activating system. Electroenceph. clin. Neurophysiol., 1949, 1: 475-486.

Lindsley, D. B., Schreiner, L. H., KNowles, W. B. and MAGOUN, H. W. Behavioral and EEG changes following chronic brain stem lesions in the cat. Electroen- ceph. clin. Neurophysiol., 1950, 2: 483-498.

MAGOUN, H. W. An ascending reticular activating system in the brain stem. Arch. Neurol. Psychiat. (Chic.), 1952, 67: 145-154.

Moruzzi, G. and MaGoun, H. W. Brain stem reticular formation and activation of the electroencephalogram. Electroenceph. clin. Neurophysiol., 1949, 1: 455-473.

Murphy, J. P. and Gelliorn, E. The influence of hypothalamic stimulation of cortically induced movements and on action potentials of the cortex.J. Neurophysiol., 1945, $8: 341-364$

ParmegGiani, P. L. On the functional significance of the hippocampal $\theta$ rhythm. In W. R. ADEY and T. TokIZANE (Eds.), Structure and function of the limbic system. Progress in brain research, Vol. 27. Elsevier, Amsterdam, 1967 : 413-441.

Passouant, P., Chadilhac, J. et Passouant-Fontaine, T. Hippocampe et réaction d'éveil. C. R. Soc. Biol. (Paris), 1955, 149: 164-166.

Ranson, S. W. and MAGOUN, H. W. The hypothalamus. Ergebn. Physiol., 1939, 41: 56-163.

SChlaG, J. D. and ChAILlET, F. Thalamic mechanisms involved in cortical desynchronization and recruiting responses. Electroenceph. clin. Neurophysiol., 1963, $15: 39-62$.

Starzl, T. E., Taylor, C. W. and Magoun, H. W. Ascending conduction in reticular activating system, with special reference to the diencephalon. $J$. Neurophysiol., 1951, 14: 461-477.

Tokizane, T., Kawamura, H. and Imamura, G. Hypothalamic activation upon the electrical activity of neo-, paleo-, and archicortices. Neurol. med.-chir. (Tokyo), 1960, 2: 63-76.

VILLABLANCA, J. The electrocorticogram in the chronic cerveau isolé cat. Electroenceph. clin. Neurophysiol., 1965, 19: 576-586.

Reference: Kawamura, H. and Domino, E. F. Hippocampal slow ("arousal") wave activation in the rostral midbrain transected cat. Electroenceph. clin. Neurophysiol., 1968, 25: 471-480. 